\title{
Embryonic Musculoskeletal System
}

National Cancer Institute

\section{Source}

National Cancer Institute. Embryonic Musculoskeletal System. NCI Thesaurus. Code C34155.

The development of the musculoskeletal system, including bone, cartilage, and muscle, from mesoderm, which begins during the third week of gestation. 